\title{
Structured Manipulable Material versus Applet in the development of Algebraic Thinking at the 1st Cycle of Basic Education
}

\author{
Nuno Santos, Paulo Afonso \& Henrique Gil \\ Escola Superior de Educação de Castelo Branco \\ Instituto Politécnico de Castelo Branco \\ Castelo Branco, Portugal \\ nunomiguelsantos88@gmail.com, paulo.afonso@ipcb.pt, hteixeiragil@ipcb.pt
}

\begin{abstract}
This investigation was conducted in the framework of the master's degree in Preschool Education and teaching of the first cycle of basic education, with students of a class of third-year elementary schooling in a Castelo Branco elementary school. Through this study, we intend to examine whether digital technology improving the number of success cases and decisionmaking in solving mathematical tasks involving repetition patterns, compared the tasks solved by using the standard blocks. This research, comparative in nature, was based on a mixed approach (quantitative and qualitative) data processing level.

Our intervention was structured in 3 phases. In the first phase, the 23 students who made up the class solved 4 tasks with repeating patterns through a work record (repeating Patterns: $A B A B$, $A B C A B C, A B B A B B$ e $A B B C C A B B C C)$. The responses of students, in the schedule of work, were analyzed through a holistic scale focused adaptation of [1], in which it was ranked each response between 0 to 2 points. From the ratings obtained by students, the class was divided into 2 homogenous groups. On the other hand, in the second phase, the students who were part of the Group (11 students) solved the same tasks using an applet, while students who comprised the Group B (12 students) solved the same tasks through manipulable material (standard blocks). To proceed to correction of the tasks of the group, we ran the' screenshots' to computer screens for each task. On the other hand, the answers of the students of Group B were analyzed using not only to work but also the photos of the compositions performed. In the third stage we proposed the same tasks, in which all students in the class, decided the issues through a worksheet.

After the data analysis we found that there were no statistically significant differences between the results obtained by the students who worked with the applet compared students who worked with manipulable materials. Although both groups of the 1st to the 3rd stage have improved substantially in terms of decision-making, as well as the number of replies considered assertive, but not so complete that work with the applet was better for the work with manipulable materials.
\end{abstract}

Keywords- Algebraic Thinking; mathematics; ICT; Manipulable Material; pattern blocks (key words)

\section{INTRODUCTION}

This research was carried out within the scope of the Master's Degree in Pre-School Education and Teaching of the 1st Cycle of Basic Education, with students of a 3rd grade class of Basic Education in a Basic School of Castelo Branco. Through this study we intend to analyze if the digital technology would improve the number of success cases and the decision making in the resolution of mathematical tasks involving repetition patterns, compared to tasks solved using the manipulable material-standard blocks. This comparative research was based on a mixed (quantitative and qualitative) approach to data processing.

Our intervention was structured in 3 phases. In the first phase, the 23 students who composed the class solved 4 tasks with repetition patterns through a worksheet (Repeat Patterns: $\mathrm{ABAB}, \mathrm{ABCABC}, \mathrm{ABBABB}$ and $\mathrm{ABBCCABBCC})$. The students' responses in the worksheet were analyzed through an adapted holistic scale scale of [1], in which each response was scored between 0 and 2 points. From the classifications obtained by the students, the class was divided into 2 homogeneous groups. In the second phase, the students who were part of group A (11 students) solved the same tasks using an applet, while the students who composed group B (12 students) solved the same tasks through the manipulable material (standard blocks). In order to correct the tasks of group A, we analyzed the 'printscreens' to the computer screens for each task. In turn, the answers of the students of group B were analyzed using not only the worksheets, but also the photographs of the compositions made. In the $3 \mathrm{rd}$ phase we proposed the same tasks, in which all the students in the class resolved the questions through a worksheet.

After the data analysis we verified that there were no statistically significant differences between the results obtained by the students who worked with the applet compared to the students who worked with the manipulable materials. We also emphasized that both groups from 1 st to 3rd stage improved substantially at the level of decision making, as well as the number of responses considered assertive, thus not being able to conclude that the work with the applet was better in relation to the work with the manipulable materials. 


\section{THE ALGERBRIAN THOUGHT IN THE FIRST YEARS OF SCHOOLING}

In the opinion of [2], as well as for [3] and [4], algebraic thinking is related to the thought of structures, namely through the understanding of relations and functions, in symbolization through the representation and analysis of mathematical structures using symbols algebraic and also in modeling. [5], [6] and [7] reinforce this notion, relating algebraic thinking to the concept of generalization. [7] points out that "(...) the focus of algebraic thinking lies in the activity of generalizing (...)" (p.87).

Thus, it is important to focus our attention, referring the concept of algebraic thinking to the first years of schooling. The [2] in its document, Curricular Guidelines, Principles and Norms for School Mathematics, as [7] emphasize algebra as a cross-cutting theme. In its document, [2], it defined 4 central axes for all pre-school education programs at the 12th grade:

"- Understand patterns, relationships and functions;

- Represent and analyze situations and mathematical structures using algebraic symbol;

- Use mathematical models to represent and understand quantitative relationships;

- Analyze the variation in different contexts" (p. 104).

[2] argues that the teaching of algebra is progressive and should be appropriate to the age group of children. As teachers we consider it important to make algebra accessible to all students. We consider that the patterns may be an excellent way to approach algebraic thinking in the first years of schooling.

\section{THE TECHNOLOGIES - APPLETS - AND THE ALGERBRIAN THOUGHT}

Society is constantly changing and these changes are also the result of the development of digital technologies. The school, as part of society, is not immune to these changes. In this perspective, we think that it is pertinent to integrate the new technologies in Mathematics.

Reflecting the theme in algebraic thinking, [8], they consider that curricula at algebra level have to adapt to these changes. Effectively, the advancement of technology can be a driver of algebra learning without drastic changes in curricula. In this perspective, the technology can be assumed as a tool of greater utility in the improvement of students' understanding in algebra. In addition, it may also influence the level of student motivation in order to develop a taste for mathematics. [9] already defended this position, considering that in the area of mathematics, digital technologies are increasingly considered as instruments of enormous value in the exploration and valorization of mathematical reasoning. In addition, [2] points out that new opportunities may arise from Technology, namely at the level of mathematical challenges, through the multiplicity of forms of representation that enhance, since it significantly increases the number of problems accessible to students and the feedback that gives.

In this investigation, we used an applet available on the NCTM website: http://illuminations.nctm.org/Activity.aspx?id=3577.

We focus our study on this applet, not only because it is recommended by the NCTM, but also because we believe it can contribute to working the mathematical concepts that we intend in an interactive way. Our perspective is in line with [10], who consider that applets can contribute "to the visualization of mathematical concepts, the exploration of contextual situations (including purely mathematical contexts), and to bridge the gap between informal and formal mathematics" (p.2). [11] centralizes applet questions in algebraic thinking when he argues that technological progress, such as dynamics and interactivity, as well as the different forms of representation of the same mathematical content, allows us to clarify and alter perspectives regarding the learning of algebraic concepts.

In Figure 1 we present the 'printscreen' of the applet to which we used:

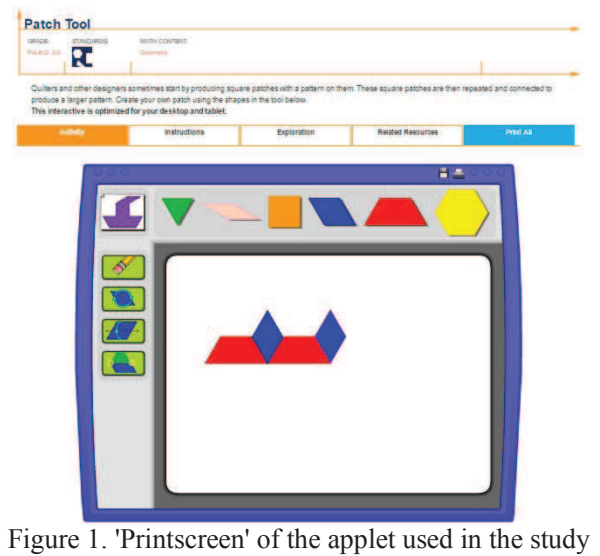

\section{PROBLEM AND OBJECTIVES OF THE STUDY}

It is our belief that applets, as well as digital resources in ICT, can have a major influence on the teaching-learning process. When we selected this topic for our investigation, it was our intention to see how the technology could improve the number of successful cases in solving activities involving repetition patterns in relation to solved activities using the standard blocks, but also to understand how the technology could help students justify their decision making in resolving activities involving repetition patterns for activities solved using the standard blocks. To this extent, we consider that the applet in which our study focused is a differentiated means of presenting activities to be performed within the classroom. Mathematics is sometimes not liked by students, and we think that using this feature can be a tool to counteract this tendency. In this perspective, we define as a theme: "The influence of digital technology on the development of algebraic thinking". For which we asked the following problem questions:

- Digital technology helps students justify their decision making in solving tasks involving repetition patterns, compared to tasks solved using the manipulative materialstandard blocks?

- Digital technology will improve the number of successful cases in solving mathematical tasks involving repetition patterns, compared to tasks solved using the manipulative material-standard blocks?

In order to answer the problem questions that we have structured we define the following objectives:

- To ascertain the strategies used by the students in the answers considered correct to describe and give continuity to 
standards and regularities before the use of ICT and after the use of ICT.

- To find out the strategies used by the students in the answers considered correct to describe and give continuity to standards and regularities, before using the manipulable materialsstandard blocks and after the use of the manipulable materials standard blocks.

- To verify the evolution verified in the two groups in relation to the number of success cases in the resolution of mathematical tasks.

This research sought to develop algebraic thinking through digital technologies, as well as to develop algebraic thinking through manipulable materials.

\section{Methodology}

This comparative research was based on a mixed (quantitative and qualitative) approach to data processing. The naturalist paradigm stands out, not neglecting, the positivist perspective. During the methodological options, we considered the perspective of [12] that they advocate a flexibility in the selection of paradigms, more than a servile adherence to a single paradigm, taking into account the defined objectives and issues. Thus, during the investigation, we compared two homogeneous groups of the same class of 23 students of the 3rd year of the 1st Cycle of Basic Education of a Basic School of the City of Castelo Branco.

From the analysis to the answers given by each student in a diagnostic test related to the algebraic thought, without the students had any previous approach to the theme of standards and regularities, followed the equivalence of the two groups. The answers given by the students were analyzed by adapting the focused Holistic scale of [1], with a score of 0 to 2 points.

The answer was classified with 0 points, when it presented the following characteristics:

- Was blank;

- The answer was clearly incorrect;

The answer was quoted with 1 point when:

- The student's response was not clear and thus, a classification of 0 or 2 points could not be assigned;

When the answers were evaluated with 1 point, one of the researchers interviewed the student, in order to understand clearly the strategy used by the student.

The answer was scored with 2 points when:

- The student answered clearly.

- The answer contained a clear justification demonstrating how the student had thought..

Considering the classifications obtained, four levels were defined (Very Good, Good, Fair and Weak) in which the punctual intervals were as follows: Very Good- [27,32], Good- [21,26], Reasonable- [15,20] and Low- [0,14]. The 23 classifications were organized as follows: randomly 4 of the 9 Very Good, 5 of the 9 Good, 1 of the 3 reasonable and 1 of the 2 weak included in group A, which later would work with the computer component, the remaining 12 Group B) would resort to manipulative materials - Standard Blocks in the second phase of the study. In Figure 2 we can observe a student from group B to solve the tasks using the Standard Blocks and in figure 3 we can observe a student from group A to use the applet.

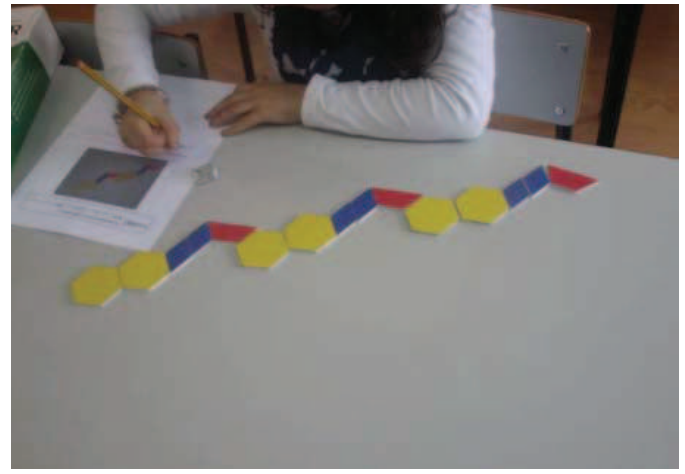

Figure 2. Student to solve the tasks with the manipulable material.

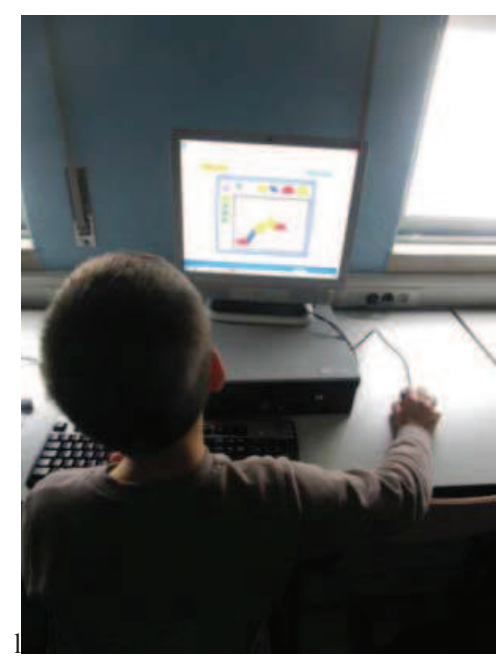

Figure 3. Task resolution through the applet.

The homogeneity of the groups was attested through analysis of the normality of the sample, as well as using the appropriate hypothesis test: Shapiro-wilk and the MannWhitney U test.

In the final phase, the 23 students performed the same tasks on paper, without using manipulatives and the applet. We wanted to verify if the students improved at the level of the algebraic thought from the 1st phase to the 3rd phase. Throughout the process, we only distribute task sheets and materials to students. We only intervened with group B, so that the students knew the operation of the applet. It is important to note that we did not give any feedback on strategies and classifications to students during the research.

After completing the data collection, we implemented two sessions with the class in which all students contacted the manipulable materials and the computer application.

\section{DATA ANALYSIS}

Data analysis was performed after each phase of the study, taking into account all stakeholders. To perform the statistical analysis of the data we used the computer program Office Excel and the statistical package SPSS 23.0.

As mentioned in the methodology, based on the results obtained by the students in the first stage, 4 of the 9 Very Good, 5 of the 9 Good, 1 of the 3 reasonable and 1 of the 2 
weak ones were a group that worked with the computer component ( Group A), the remaining 12 worked with the Standard Block Materials (Group B). As the sample size was relatively small, we selected the Shapiro-Wilk test to test the normality of the sample for both groups. We define for $\alpha$ the following hypotheses: H0: The distribution is normal $(\alpha=$ 0.05). H1: The distribution is not normal $(\alpha=0.05)$. For group A, we obtained a p-value of 0.015 , ie less than 0.05 . Thus, there were conditions to reject the null hypothesis, so the distribution has no normal tendency. For group B, the p-value obtained was 0.007 and we considered that there were conditions to reject the null hypothesis and thus the distribution does not have a normal tendency. As the distribution had no normal trend, we considered a nonparametric hypothesis test to verify if the groups are homogeneous. To prove the homogeneity of the two groups, we selected the non-parametric Mann-Whitney U test. Thus, we define the following hypotheses: H0: There are no significant differences between the means of the two groups $(\alpha$ $=0.05) ; \mathrm{H} 1$ : There are significant differences between the means of the two groups $(\alpha=0.05)$. Since we obtained a pvalue of 0.803 , greater than $\alpha$, there are no conditions to reject the null hypothesis, so we assume that the groups are equivalent.

In the second phase of the study, we verified that the group that worked with the applet obtained very positive rankings, with 10 students at a very good level and one student was classified as good. In relation to the group that worked with the manipulable material we noticed some evolution, registering 8 students with a Very Good rating, 2 students with a Good level and 2 students with a Reasonable level.

On the other hand, in the 3rd phase, the 11 students who were part of the group that worked with the applet obtained a Very Good rating. Similarly, we verified that the students of the group that worked with the manipulative material obtained 11 Very Good, 1 Good. At this stage, the normality of the samples was studied. We define the following hypotheses: H0: The distribution is normal; H1: The distribution is not normal. In the case of the group that used the applet, as the classifications were, constant (Very Good) the distribution had no normal tendency. For the group that used the manipulable materials, as the obtained p-value was of 0,000 , that is inferior to 0,05 , there are conditions to reject the null hypothesis, therefore the distribution also does not have normal tendency.

As the distribution of the two groups did not have normal tendency, we selected a non-parametric test, in order to determine if the groups remained homogeneous in the third stage. To prove the homogeneity of the two groups, we opted for the non-parametric Mann-Whitney test. We define the following hypotheses: H0: There are no significant differences between the means of the two groups $(\alpha=0.05)$; H1: There are significant differences between the means of the two groups $(\alpha=0.05)$. As the obtained $p$-value was 0.166 , that is, greater than 0.05 , there were no conditions to reject the null hypothesis, so we assumed that the groups were also equivalent in the third step. In this way we can not state with statistical confidence that those who worked with the applet obtained better results, in relation to those who worked with the manipulable materials or vice versa.

Later, we analyzed the classification of intragroup data, comparing the results of the $1 \mathrm{st}$ and $3 \mathrm{rd}$ phase. In order to determine if there were significant differences in the group that worked with the applet (group A) between the 1st phase and the 3rd phase. Thus, we formulated the following hypotheses: H0: There are no statistically significant differences between the 1 st and 3 rd phase for group $\mathrm{A}(\alpha=$ $0.05) ; \mathrm{H} 1$ : There are statistically significant differences between the 1 st and 3rd phase for group A $(\alpha=0.05)$. In this case, we used the nonparametric Wilcoxon mean comparison test for paired samples. As the p-value obtained was 0.007 , ie less than 0.05 , there are conditions to reject the null hypothesis, so there are differences between the 1 st and $3 \mathrm{rd}$ phase in relation to group A.

In order to determine if there were significant differences in the group that worked with the manipulable materials (group B) between the 1st phase and the 3rd phase, we formulated the following hypotheses: H0: There are no differences between the 1 st and 3rd stage with respect to group B $(\alpha=0.05)$; H1: There are differences between the 1 st and 3 rd stage regarding group $\mathrm{B}(\alpha=0.05)$. As previously we chose the Wilcoxon test for paired samples. Since we obtained a p-value of 0.007 , ie less than 0.05 , there were conditions to reject the null hypothesis, so we considered that there were differences between the 1st and 3rd phase in relation to group B, which worked with the manipulable material.

In this study it was also our intention to make an analysis regarding the justifications and positions of the students. In this perspective, we have tried to identify strategies used in the "nearer" generalization, in a first phase and later in the "next" generalization. At the level of the first phase we found that the students in group A used 7 different strategies to justify their positions. In the first phase, for the "next" generalization, the students of the group that worked with the applet (Group A) resorted to 5 strategies, emphasizing the strategy of "counting piece by piece". On the other hand, students faced the tasks that implied close generalization, still in the first phase, also resorted to 5 strategies, 3 being equal to those of the generalization «more» next ("counting piece by piece", "relation with multiple" and " identification of the replay module '). In the two typologies of generalization, the strategy of "piece-by-piece counting" was highlighted as the one with the highest absolute frequency. In relation to the 3 rd phase, the subjects in group A used a total of 8 different strategies. For the "closer" generalization of the 6 strategies used, the "pieceby-piece counting" strategy recorded the highest absolute frequency, as well as in tasks involving close generalization.

In turn, we verified that in the first phase the students of group B resorted to 5 different strategies to justify their decision making, for the two generalizations. In this phase, for the "closer" generalization, the students in this group used 4 strategies to justify their decision making, evidencing the strategy of "counting piece by piece" with more absolute frequency. We also verified that these subjects, faced with the tasks that implied close generalization, still in the first phase, 
resorted to 4 strategies, returning to be the strategy of "counting piece by piece" also the one that registered more frequency. Regarding the $3 \mathrm{rd}$ phase, we found that the students of group B, used 7 different strategies to justify their position in the total of the two generalizations. At this stage, and with regard to the "closer" generalization, the subjects used four strategies, especially the one-to-one counting strategy with the highest absolute frequency. Also in the same phase, for the next generalization, we recorded 6 different strategies in the answers of the students that composed the group B, highlighting the strategy of "counting piece by piece».

\section{CONCLUSIONS}

Before presenting the main findings of the study, it should be noted that the results obtained are confined to the study subjects, and it is not our intention to make any kind of generalization. When we analyzed the answers of the students of group A and Group B in the first and the third phase of the study for the "next" generalization and for the generalization next, we found that the strategy of "counting piece by piece" was the one most used by students to justify their options. We also determined that the subjects of the two groups obtained relatively uniform classifications in the 3 rd phase. To reach this conclusion, we used the Mann-Whitney U non-parametric statistical test, since the distribution had no normal trend. Through the test, we verified that there were no statistically significant differences between the means of the two groups in the $3 \mathrm{rd}$ phase, thus not being able to declare that the work with the computer application had been better than the work with the manipulative material-standard blocks.

Thus, we advise both tools to develop algebraic thinking, since the statistical test used to compare the scores obtained by the students of the two groups in the first and third stages allowed us to verify that there were statistically significant differences between the 1 st and 3rd phase of the study.

We also found, using the Wilcoxon statistical test, that the students of both groups evolved their rankings significantly from the 1 st to the 3 rd phase of the study.

This study allowed us to conclude from the MannWhitney U non-parametric statistical test performed in the 3rd phase that there were no significant differences between the means of the two groups, thus verifying that the groups were equivalent.

\section{REFERÊNCES}

[1] R. Charles, F. Lester, and P. O'Daffer, "How to evaluate progress in problem solving”. Reston,VA: NCTM, 1987.

[2] NCTM, "Princípios e Normas para a Matemática Escolar". Lisboa: APM, 2007.

[3] A. Borralho and E. Barbosa, "Exploração de padrões e pensamento algébrico". In I. Vale and A. Barbosa (Orgs.), Patterns: multiple perspectives and contexts in mathematics education (Projeto Padrões) (pp. 59- 68). Viana do Castelo: Escola Superior de Educação, Instituto Politécnico de Viana do Castelo, 2009.

[4] I. Vale and T. Pimentel, "Padrões em matemática: uma proposta didática no âmbito do novo programa para o ensino básico". Lisboa: Texto, 2011.

[5] M. Blanton, and J. Kaput, "Characterizing a classroom practice that promotes algebraic thinking". Journal for Research in Mathematics Education, vol. 36, ed. 5, 2005, pp. 412-446.

[6] J. Kaput, "Teaching and learning a new algebra with understanding". In E. Fennema and T. Romberg (Eds.), Mathematics classrooms that promote understanding. Mahwah, NJ: Erlbaum, 1999, pp. 133-135.

[7] A. Canavarro, "O pensamento Algébrico na aprendizagem da matemática nos primeiros anos". Quadrante, vol. XVI, n²2, 2007, pp. 81118.

[8] K. Stacey and H. Chick, "Solving the problem with algebra". In K. Stacey, J. Chick and M. Kendal (Eds.) The future of the teaching and learning of álgebra: the 12th ICMI study. Boston: Kluwer Academic, 2004, pp. 1-20.

[9] J. Ponte and A. Canavarro, "Matemática e novas tecnologias". Lisboa: Universidade Aberta, 1997.

[10] A. Heck, P. Boon, C. Bokhove and G. Koolstra, "Applets for learning school algebra and calculus: experiences from secondary school practice with an integrated learning environment for mathematics". 1st JEM Workshop, Lisbon, 2007 [Online], Available: http://uu.academia.edu/ChristianBokhove/Papers/219885/Applets_for_L earning_School_Algebra_and_Calculus

[11] J. Duarte, "Tecnologias para desenvolver o pensamento algébrico". Atas do Congresso Internacional ticEDUCA, 2012, pp. 1927-1944.

[12] L. Cohen, L. Manion and K. Morrison, "The context of educational research". In L. Cohen, L. Manion and K. Morrison (Orgs.), Research methods in education, London: Routledge Falmer, 2000, pp. 1-2. 